\title{
A propósito de una nueva Ley
}

Luis FERNANDO SAURA

Remitida por el Senado al Congreso de los Diputados, se publicó en el B.O.C.G. número 151,1 de uno de junio de 1989, una Proposición de Ley de reforma del Código civil, en aplicación del principio de no discriminación por razón de sexo.

Apremiado por la urgencia de preparar un trabajo para la Revista Anales de la Facultad de Derecho de la Universidad de Alicante, me pareció sugestivo realizar unos comentarios, siquiera a vuela pluma, en torno a la referida Proposición de Ley. Y, en efecto, corriendo el pasado mes de junio, y dándolo ya por concluido, me apresuré a entregarlo para asegurar su inclusión en el número presto, pensaba, a ver la luz. Mas como de sólito sucede, la confección de meritada Revista se ha ido demorando, hasta dar lugar a que lo estudiado como Proposición sea, hoy, flamante realidad legal.

Ante esta tesitura cabían dos posibilidades; la primera, respetar el texto original del artículo, y añadir como «addenda» las innovaciones introducidas por la Ley al Proyecto; la segunda, rehacer el trabajo aprovechando lo que del anterior viniera al caso y componiendo o recomponiendo lo que menester fuera.

Me ha parecido más adecuada la segunda fórmula, aunque en ciertos casos recoja, a pie de página, comentarios, críticas u opiniones formuladas al hilo de la Proposición, en tanto que algunos han sido recogidos por la Ley, mientras que otros, aún no habiéndolo sido, me sigan pareciendo interesantes.

En cualquier caso, y según se desprende de lo anteriormente expuesto, se trata de salvar lo máximo, y he procurado llevarlo a efecto con abso- 
luto rigor, es decir, comenzando por el mismísimo título que, hasta este momento, ha sido "A propósito de una Proposición de Ley».

La Ley 11/1990 de 15 de octubre, publicada en el B.O.E. del día 18 del propio mes, sobre reforma del Código civil en aplicación del principio de no discriminación por razón de sexo, evidentemente escueta, consta de un Preámbulo, ocho artículos y una Disposición transitoria. ${ }^{1}$ Sistemática que es aconsejable seguir, analizando cada uno de sus aspectos en este estudio, y así:

\section{PREÁMBULO}

Recordando las reformas del Código civil por las leyes $11 / 81$ de 13 de mayo y $30 / 81$ de 7 de julio, que adaptaron sus preceptos al principio de igualdad proclamado en los artículos 14 y 32 de la Constitución, y citando, asimismo la Ley 21/1987 de 11 de noviembre, subraya el Preámbulo la subsistencia en dicho cuerpo legal de algunos preceptos en los que «para determinar la eficacia de ciertas relaciones y situaciones jurídicas, se atiende a criterios que encierran o una preferencia o trato inadecuado por razón de sexo».

Consiguientemente, la Ley que nos ocupa «pretende eliminar las discriminaciones que por razón de sexo aún perduran en la legislación civil, y perfeccionar el desarrollo normativo del principio constitucional de igualdad».

Justificados los motivos de la reforma, se distribuyen en los ocho artículos de que consta la ley, las distintas situaciones menesterosas de corrección; artículos que procedemos à comentar:

\section{ARTÍCULO $1 .^{\circ}$}

«Los apartados 2,3,5 y 8 del artículo 9 del Código civil, tendrán la siguiente redacción: ${ }^{2}$

2.- «Los efectos del matrimonio se regirán por la ley personal común de los cónyuges al tiempo de contraerlo; en defecto de esta ley, por la ley personal o de la residencia habitual de cualquiera de ellos, elegida por ambos en documento auténtico otorgado antes de la cele- 
bración del matrimonio; a falta de esta elección por la ley de la residencia habitual común inmediatamente posterior a la celebración, y, a falta de dicha residencia, por la del lugar de celebración del matrimonio.

La separación y el divorcio se regirán por la ley que determina el artículo 107».

3.- «Los pactos o capitulaciones por los que se estipule, modifique o sustituya el régimen económico del matrimonio serán válidos cuando sean conformes bien a la ley que rija los efectos del matrimonio, bien a la ley de la nacionalidad o de la residencia habitual de cualquiera de las partes al tiempo del otorgamiento».

Una primera aproximación a la redacción de los dos recogidos apartados, pone de relieve el hecho de la sustitución de las menciones específicas a relaciones personales o patrimoniales de los cónyuges - que justificaban, en cierta forma, su anterior contenido- por la frase «efectos del matrimonio», englobando en ella tanto los aspectos personales como los patrimoniales, aunque "de facto», se siga debiendo interpretar el apartado segundo como referido a aquéllos, y el tercero a éstos.

Parece oportuna, condignamente con la finalidad perseguida por la Ley que nos ocupa, la supresión del inciso último del número $2 .^{\circ}$ del artículo 9 , ya que - si bien con carácter subsidiario y en defecto de ley nacional común durante el matrimonio- primaba al marido en detrimento del derecho de la esposa, igual, sin embargo al de aquél, a partir de las reformas del Código civil en el año 1981.

En estricta observancia, pues, del principio de no discriminación, establece la Ley un orden de preferencias en la aplicación de la norma correspondiente a las situaciones matrimoniales que se puedan plantear. en el futuro, buscando basamento en criterios de asepsia y objetividad - elogiables, desde luego, empero la redacción del texto no sea precisamente una joya de precisión - e introduciendo, por vía normativa o por consenso de ambos cónyuges, fórmulas de variada gama que puedan satisfacer cualquier tipo de situaciones que en la práctica puedan darse.

La escala de prioridades de tales previsiones podría esquematizarse en la forma siguiente: $1 .^{\circ}$ Regulación de efectos por la ley personal co- 
mún de los cónyuges al tiempo de contraer matrimonio. $2 .^{\circ}$ En defecto de la anterior, deja la Ley en estudio autonomía a los cónyuges, en cuanto establece la aplicación de la ley personal o de la residencia de cualquiera de ellos, siempre que la misma hubiera sido elegida de común acuerdo por los contrayentes, y expresada en documento auténtico con anterioridad a la celebración del matrimonio. $3 .^{\circ} \mathrm{A}$ falta de elección, se regularán los efectos del matrimonio por la ley de la residencia habitual común inmediatamente posterior a su celebración. $4 .^{\circ}$ Finalmente, y en ausencia de todos los presupuestos anteriores, los efectos del matrimonio se someterán a la ley del lugar de celebración del matrimonio.

A tenor de lo dicho, tal vez no hubiera sido importuna la mejora del texto, mediante una doble aclaración por el legislador acerca, la primera, de qué se debe entender por documento público a estos fines; la segunda, sobre las razones que abonan la conveniencia de que la elección de la norma haya de manifestarse con anterioridad a la celebración del matrimonio.

A mi juicio, y respecto del primer punto, hubiera parecido acertado -eludiendo al propio tiempo connotaciones semánticas o uso de nomenclaturas más propias de otras disciplinas- sustituir la expresión «documento auténtico» por la de «documento fehaciente» o «documento público» si se quiere.

En cuanto al segundo supuesto, si se nos exigiera, aquí y ahora, una explicación relativa al porqué de la manifestación de la elección de la norma con anterioridad a las nupcias, acaso únicamente se nos ocurriera el manido y tópico argumento - por cierto, reducto aún latente del trasnochado discurso «machista»- de que, una vez celebrado el matrimonio, amengua la libertad y la decisión puede ser impuesta de forma más o menos sutil, capciosa, o, incluso, coactiva por el cónyuge más fuerte y astuto, virtudes que nuestra tradición ha arrogado siempre al varón y ha escamoteado a la hembra.

Mas también cupiera explicar la disposición como dirigida a impedir, en un momento determinado, la elección de aquella ley que, atendidas las circunstancias, pudiera implicar fraude legal. 
Tampoco parece especialmente feliz la referencia a que, en defecto de elección por los cónyuges de la norma aplicable a los efectos de su matrimonio, les deba ser aplicada la ley de su residencia habitual común inmediatamente posterior a la celebración del matrimonio. ¿Cuál es la razón de que no pueda ser la ley de la última residencia común, más fácilmente acreditable siquiera por proximidad temporal?

No exige comentario alguno, por su claridad, la remisión del párrafo segundo del apartado $2 .^{\circ}$ del artículo 9 al artículo 107. Solamente apuntar, si acaso, que aun a riesgo de caer en redundancia o sobreentendido, no hubiera estado de más añadir, inmediatamente detrás del último citado artículo, la frase «de este Código».

Con todo, mayor ambigüedad y confusión se aprecia, a mi modo de ver, en el apartado $3 .^{\circ}$ del artículo 9, el cual, en su redacción anterior a la Ley que analizamos, establecía: «Las relaciones patrimoniales entre los cónyuges, a falta o por insuficiencia de capitulaciones permitida por la ley de ellos...». En su actual redacción se amplía el elenco, incluyendo estipulación, modificación o sustitución del régimen económico determinado por la ley que rija los efectos del matrimonio, declarando válidos los pactos o capitulaciones cuando sean conformes bien a referida ley, bien a la ley de la nacionalidad o de la residencia habitual de cualquiera de los contrayentes al tiempo del otorgamiento.

Ambigüedad derivada, posiblemente, de que el artículo 9 del Código no experimentara modificación alguna por la Ley de mayo de 1975 introduciendo la mutabilidad del régimen económico-matrimonial constante matrimonio, y consagración, por ende, de la facultad de otorgar capitulaciones antes o durante aquél. Pero ambigüedad que se acentúa: 1. ${ }^{\circ} \mathrm{Al}$ hablar sólo de los efectos del matrimonio, mezclando, incomprensiblemente, los personales y los patrimoniales, sin que la referencia inicial a pactos o capitulaciones desvirtúe un ápice la perplejidad que provoca la reciente costumbre del legislador de eludir la designación de las cosas por su nombre, al menos en algunos casos. $2 .^{\circ}$ Los pactos o capitulaciones pueden ser conformes tanto a la ley que rija los efectos del matrimonio, como a la de la nacionalidad o residencia habitual de cualquiera de los contrayentes al tiempo del otorgamiento, hipótesis que enunciada así no plantea problema alguno. Sin embargo, tales pactos 
pueden ser válidos conforme a la ley que rija los efectos del matrimonio, pero nulos o ineficaces de acuerdo con la ley nacional o de la residencia habitual de cualquiera de los cónyuges al tiempo del otorgamiento, en cuyo supuesto ¿qué ley sería la aplicable? El sentido común parece indicar habría de ser la que rija los efectos del matrimonio - enunciada en primer lugar del número $3 .^{\circ}$ del artículo-, pero la redacción actual del mismo no establece primacías o prioridades, deduciéndose de su tenor que serán válidos los pactos ya se ajusten a dicha ley, ya lo hagan a cualquiera otra de las referidas, imprecisión que, provocando el caso, bien pudiera calificarse de auténtico desatino.

Pero, aún más, el respaldo legal a la validez de meritados pactos o capitulaciones, cuando sean conformes con cualquiera de las leyes expresadas, es tanto como introducir el germen o semilla de toda clase de conflictos. En efecto, ¿por qué aplicar la ley de uno de los cónyuges y no la del otro a la hora de interpretar las capitulaciones, cuando, al no distinguirse, tanto una como otra gozan de trato igual, de idéntico amparo y susceptibilidad de aplicación?

Al propio tiempo, queda, incomprensiblemente, posibilitado el fraude de ley, al permitir a los cónyuges, en cada momento y a su libérrimo arbitrio y conveniencia, exigir la aplicación de la norma que mejor cuadre a sus intereses.

De otra parte, introduce la Ley que nos ocupa una ampliación a la Proposición, introduciendo, como ya dijimos, los apartados 5 y 8 del artículo 9, con nueva redacción respecto de la que hasta ahora han tenido. Procederemos, pues, a analizar el primero de los referidos:

5.-Referente a la adopción, entiendo conveniente hacer una previa y brevísima, introducción histórica:

A. Directrices imperantes en torno a la cuestión, desde la redacción originaria del Código civil hasta la reforma del Título Preliminar del mismo:

1.-Debe regularse la capacidad para adoptar y ser adoptado por las respectivas leyes nacionales. 
2.-La forma de la adopción se ajustará a la establecida por la legislación del país donde tuvo lugar. Pero si el adoptado en país extranjero es español menor de edad, la autorización judicial exigida por el Código (a la sazón por el artículo 178) habrá de otorgarse por las autoridades españolas.

3.-Los efectos de la adopción se regirán por la ley del adoptante. ${ }^{4}$

B. Directrices del Código civil tras la reforma de su Título Preliminar hasta la Ley en estudio:

1.-La capacidad para adoptar y los efectos de la adopción, se regirán por la ley del adoptante.

2.- Se observará la ley personal del adoptado en lo referido a su capacidad, consentimiento y modo de suplirlo o complementarlo.

3.-Para la constitución de la adopción serán competentes las autoridades de la nacionalidad del adoptante.

4.- Las formalidades del acto se ajustarán a la ley del lugar en que se constituya la adopción, sin perjuicio de lo dispuesto en el artículo 11, 3 del Código civil.

C. La redacción actual del apartado 5 del artículo 9 del Código civil:

A mi juicio, el precepto dedicado a la adopción se debe analizar desde una triple perspectiva:

1. Adopción constituida por Juez español.

2. ${ }^{a} \quad$ Constituida por los Cónsules españoles.

3. ${ }^{\text {a }}$ Constituida por la legislación extranjera.

El propio apartado 5 nos va a indicar cada uno de los extremos a encajar en la anterior división tripartita, y así:

Con referencia al punto primero:

A. La adopción constituida por Juez español se regirá, en cuanto a los requisitos, por lo dispuesto en la Ley española. 
B. Se observará la ley nacional del adoptando en lo referido a capacidad y consentimientos necesarios: $1 .^{\circ} \mathrm{Si}$ reside habitualmente fuera de España. 2. ${ }^{\circ}$ Aunque resida en España, si no adquiere, en virtud de la adopción, la nacionalidad española.

C. A petición del adoptante o del Ministerio Fiscal, el Juez, en interés del adoptando, podrá exigir, además, los consentimientos, audiencias o autorizaciones requeridas por la Ley nacional o la de la residencia habitual del adoptante o del adoptando.

Relativamente al punto segundo:

A. Siempre que el adoptante fuere español y el adoptando estuviere domiciliado en la demarcación consular, tendrán los Cónsules españoles, para la constitución de la adopción, las mismas atribuciones que el Juez.

B. En este caso, la propuesta previa para la adopción será formulada por la entidad pública correspondiente al último lugar de residencia del adoptante en España. No será necesaria propuesta previa, si el adoptante nunca tuvo residencia en España, pero el Cónsul habrá de recabar de las autoridades del lugar de residencia del adoptante, informes suficientes para valorar su idoneidad:

En lo que atañe al tercer extremo:

A. En la adopción constituida por la legislación extranjera, regirá la ley del adoptando en lo referido a capacidad y consentimientos necesarios.

B. Dichos consentimientos podrán prestarse ante una autoridad del país en que se inició la constitución o, posteriormente, ante cualquier otra autoridad competente.

C. Si se trata de la adopción de un español, será necesario el consentimiento de la entidad pública correspondiente a la última residencia del adoptando en España.

Expuesto lo anterior, conviene advertir que entre la redacción del apartado 5 del artículo 9 del Código civil dada por Decreto de 31 de 
mayo de 1974, y la que realiza la Ley que tenemos en estudio, se promulgó la de 11 de noviembre de 1987 modificando el Código civil y la Ley de Enjuiciamiento Civil en materia de adopción; circunstancia que es de importancia tener en consideración a la hora de interpretar el nuevo texto. Pero, como el reto es tentador, aunque razones de espacio veden la profundización que exige la materia no es fácil resistirse a apuntar algunas ligerísimas observaciones.

En efecto, establece el inciso primero del párrafo primero del apartado que absorve nuestra atención, una regla general consistente en la afirmación de que la adopción constituida ante Juez español se regirá, en cuanto a los requisitos, por la ley española.

Lo primero que preocupa de la lectura de referido inciso es la necesidad de determinar a qué requisitos se refiere y en qué casos, pues, evidente será, que la adopción de español por español habrá de ajustarse en todo a lo que establecen nuestras leyes; pero iy si se trata de adopción de español por extranjero o viceverse?, ¿se refiere el precepto a requisitos procesales o sustanciales, o a ambas?

Es claro que los requisitos procesales son de observancia absolutamente imperativa, a tenor del número 2 del artículo $8, \mathrm{y}$ del inciso $1 .^{\circ}$ del número 1 del artículo 11, ambos del Código civil (y no se debe olvidar que la Ley de 1987 reforma la Ley de Enjuiciamiento Civil en sentido paralelo y armónico a como lo hace con el Código civil). No obstante, ¿Serán, asimismo, de ineludible aplicación requisitos puramente sustantivos como los establecidos en los artículos 175 y 176 del Código civil?

Seguramente, el último interrogante lo pueda aclarar el inciso siguiente del propio párrafo primero, cuando dispone que se observe la Ley nacional del adoptando, en alguno de los dos supuestos siguientes: $1 .^{\circ}$ Que habitualmente residiere fuera de España. 2. ${ }^{\circ}$ Que aun residiendo en España, no adquiera la nacionalidad española en virtud de la adopción.

En ambos casos, está contemplando el precepto la adopción de extranjero en procedimiento seguido ante Juez español, entre otras razones en cuanto impone la observancia de la ley nacional de adoptando, 
dando por supuesto, en relación con el inciso anterior, de que no es la española.

Es más, parece contemplar el Código el supuesto de adopción de extranjero por extranjero, según se desprende del segundo requisito establecido, cual es el referido a la no obtención por el adoptando, en virtud de la adopción, la nacionalidad española (evidentemente, si es español el adoptando, ya tiene esta nacionalidad; si lo fuera el adoptante la comunicaría al adoptando por virtud del artículo 18 del Código, salvo caso de que el adoptando tuviera más de 18 años, pero qué difícil es en nuestra actual normativa la adopción de persona mayor de edad, a la vista del número 2 del artículo 175 del Código civil).

Ampliando lo apuntado, el párrafo siguiente de este apartado 5, permite al Juez, en interés del adoptando y a petición del adoptante o del Ministerio Fiscal -cuya intervención en este tipo de procesos es preceptiva - exigir, además, los consentimientos, audiencias, o autorizaciones requeridas por la ley nacional o la de la residencia habitual de adoptante y adoptando.

Tal cautela puede responder, a mi juicio, a la necesidad de sustituir la propuesta de adopción formulada por la entidad pública correspondiente, a que se refiere el artículo 1.829 de la Ley de Enjuiciamiento Civil -en la adopción entre extranjeros presupuesto de casi imposible cumplimiento-, por la concesión al Juez de la facultad, a petición de adoptante o del Ministerio Fiscal, de acudir a ley distinta de la española, acaso menos rígidas, para recabar los consentimientos, autorizaciones y demás que pueda precisar para emitir una resolución fundada en derecho, pero, sobre todo, justa. Y esta opinión podría reforzarse acudiendo al párrafo siguiente del propio apartado 5, que suple la presentación de la propuesta previa, en el caso de no haber residido nunca en España el adoptante, por la reclamación de informes a las autoridades del lugar donde resida el adoptante, para, mediante ellos, valorar la idoneidad del interesado.

Novedad destacable, es la atribución - ya a cara descubierta- de facultades judiciales a los Cónsules en los referido a la constitución de 
la adopción; si bien con dos límites: que sea español el adoptante; que resida el adoptando en su demarcación consular.

Asimismo, es de reiterar - por lo que pueda significar de futuro como base para otras interpretaciones- la posibilidad de sustituir la propuesta previa del ente público, por el acopio de informes recabados a las autoridades del lugar donde resida el interesado, para, mediante ellos, conformar su opinión y fundamentar su decisión relativa a idoneidad o no del aspirante.

El párrafo final del apartado 5 del artículo 9, contempla la hipótesis relativa a la adopción constituida por autoridad extranjera competente, disponiendo, para este caso, que regirá la ley del adoptando en cuanto a capacidad y consentimientos necesarios; añadiendo, inmediatamente, que los consentimientos exigidos por tal ley podrán prestarse bien ante una autoridad del país en que se inició la constitución de la adopción, bien posteriormente ante cualquier otra autoridad competente.

La impresión más notoria que provoca la lectura del anterior párrafo es, cuando menos, la de una insoportable duda ¿no nos estaremos introduciendo en corral ajeno?

Lo que si parece oportuno es el inciso final del párrafo que comentamos, ordenando que para la adopción de un español será necesario el consentimiento de la entidad pública correspondiente a la última residencia del adoptando en España.

Es pertinente el inciso en consonancia con nuestra propia legislación que siempre tiende a procurar se aplique prioritariamente la ley nacional en tema de adopciones. De otra parte, aun siendo posible a tenor de la ley extranjera la adopción del español sin referido consentimiento, es claro que en España no tendría efecto alguno. Solamente en un caso no sería necesario tal consentimiento, si nos atenemos al tenor del precepto, cuando el adoptando español nunca hubiera residido en España, caso no infrecuentes en los tristes años de la emigración española, principalmente a los países más desarrollados de Europa.

Abordamos, finalmente, del artículo primero de la Ley 11/90, el estudio del apartado 8 del artículo 9 del Código civil. Dice su nueva redacción: 
«La sucesión por causa de muerte se regirá por la ley nacional del causante en el momento de su fallecimiento, cualquiera que sean la naturaleza de los bienes y el país donde se encuentren. Sin embargo, las disposiciones hechas en testamento y los pactos sucesorios ordenados conforme a la ley nacional del testador o del disponente en el momento de su otorgamiento, conservarán su validez aunque sea otra la ley que rija la sucesión, si bien las legítimas se ajustarán, en su caso, a esta última. Los derechos que por ministerio de ley se atribuyan al cónyuge supérstite se regirán por la misma ley que regule los efectos del matrimonio, a salvo siempre las legítimas de los descendientes.

Se puede desglosar el número en cuestión en la forma siguiente:

A. La sucesión por causa de muerte se regirá por la ley nacional del causante al tiempo de su fallecimiento.

B. Las disposiciones hechas en testamento y los pactos sucesorios ordenados conforme a la ley nacional de testador o disponente al tiempo de su otorgamiento, conservarán su calidez, aunque sea otra la ley que rija la sucesión.

De donde:

1.-De la confrontación de ambos párrafos hay que concluir que el causante cambió, al menos una vez, de nacionalidad.

2.-Que al tiempo de su fallecimiento el causante no había otorgado otro testamento, empero el cambio de nacionalidad, o, de haberlo hecho carecería éste de eficacia relativamente a las disposiciones ínsitas en el testamento ajustado a su ley nacional al tiempo del otorgamiento del mismo; y ello, desde la perspectiva de todos los supuestos contemplados en el número $1 .^{\circ}$ del artículo 11 del Código civil, en cuanto dispone: «Las formas y solemnidades de los contratos, testamentos y demás actos jurídicos, se regirán por la ley del país en que se otorguen; también serán válidos los celebrados con las formas y solemnidades exigidas por la ley aplicable a su contenido, y, al cabo, dando validez a los celebrados conforme a la ley personal del disponente que sería, en nuestro caso, la que ostentara al tiempo del otorgamiento. 
3.--En definitiva, aun siendo de aplicar la ley del causante al tiempo de su fallecimiento, lo será en todo salvo en lo referido a las disposiciones testamentarias o pactos sucesorios ordenados conforme a la ley nacional del testador o del disponente al tiempo del otorgamiento. Resaltando, en cuanto a los pactos sucesorios, que la doctrina se inclina por señalar la irrevocabilidad como una de sus características esenciales.

4.-Con referencia a las legítimas, sigue ordenando el precepto que se ajustarán a la ley que rija la sucesión, lo que pudiera crear conflictos en el caso de que, a tenor de la legislación aplicable a las disposiciones testamentarias, quedaran aquéllas incólumes, pero, sin embargo, de la aplicación de la ley que rija la sucesión resultara haber dispuesto el testador en perjuicio de sus legitimarios.

5.- Novedad de la ley, el último párrafo de este apartado se limita a disponer que los derechos que la ley atribuye al cónyuge supérstite se regirán por la misma ley que regule los efectos del matrimonio; es decir, por la prevista en el número 2 del artículo 9 del Código civil, a cuyo comentario nos remitimos.

Finalmente, es claro el espíritu final de este párrafo, al establecer que, sea cualquiera la ley que se aplique en la regulación y estimación de los derechos del cónyuge supérstite, siempre habrán de quedar a salvo las legítimas de los descendientes.

\section{ARTÍCULO SEGUNDO}

Persistiendo en esta cía de corregir discriminaciones, se proceda a nueva redacción de los artículos 14, 14, 1.066 y 1.267 del Código civil, innovaciones que interesa comentar siguiendo el mismo orden en que se enuncian: ${ }^{5}$

Artículo 14.-No ofrecen variación el número $1 .^{\circ}$, ni el párrafo primero del número $2 .^{\circ}$ de dicho artículo, si bien el último se corresponde con el inciso primero del correlativo en su anterior redacción.

Sí es de resaltar el párrafo segundo del mismo número 2 , cuando establece que el adoptado no emancipado adquiere, por la adopción, la vecindad civil de los adoptantes. Reseña lógica en pura consecuencia 
con la concepción actual de la adopción y la equiparación del hijo adoptado al por naturaleza, según dispone el artículo 108, del Código civil.

El número $3 .^{\circ}$ del artículo plantea diversos supuestos, que se pueden desbrozar en:

A. Caso de distinta vecindad de los padres al tiempo del nacimiento o de la adopción del hijo. Quedará sujeto éste a la que ostente el cónyuge cuya filiación respecto de aquél hubiera sido establecida antes; en su defecto, tendrá la del lugar de nacimiento, y, en último término, la vecindad de Derecho común.

Una más rigurosa puntualización exige reseñar lo siguiente: a) Respecto del hijo natural matrimonial, lo normal será la determinación de su filiación, conforme a lo establecido en el artículos 115 número $1 .^{\circ}$ del Código civil (por supuesto, es de descartar, a estos fines, el número $2 .^{\circ}$ de dicho artículo); b) Con referencia al hijo natural no matrimonial, lo usual será el supuesto del número $4 .^{\circ}$ del artículo 120 del propio Código, prevaleciendo la vecindad de la madre (no olvidemos que, hasta ahora, tratamos de los supuestos normales de determinación de la filiación tanto matrimonial como extramatrimonial); c) En la adopción, o se realiza por una sola persona, a tenor del número $4 .^{\circ}$ del artículo 175 del Código civil, o por ambos cónyuges, debiéndose incluir en la segunda hipótesis la vecindad derivada del previo establecimiento, en razón de simultaneidad; d) No establecida o no acreditada prioridad en favor de alguno de los padres, tendrá el hijo la vecindad del lugar de nacimiento, $y$, en última instancia, la vecindad de derecho común. Soluciones salomónicas las dos finales que, paradójicamente, podrían coincidir con la vecindad de alguno de los padres.

B. Concede, la Ley que nos ocupa, la posibilidad de que los padres - de común acuerdo se supone- o el que de ellos tenga la patria potestad, puedan atribuir al hijo la vecindad civil de cualquiera de ellos, interin no transcurran los seis meses siguientes al nacimiento o a la adopción.

Excepción lógica al precepto del párrafo anterior, que se justifica, caso de común acuerdo de los padres, por su interés de procurar al hijo la que entiendan más beneficiosa parạ él; y en cuanto a la actuación 
del cónyuge que ejerza o le hubiere sido atribuida la patria potestad, por el anhelo legítimo de que comparta su propia vecindad, quedando sujeto a idénticas normas que él mismo, más próximas y conocidas.

C. A diferencia de la anterior redacción, y tal vez por influencia del artículo $180,3 .^{\circ}$ del Código civil (la extinción de la adopción no es causa de pérdida de la nacionalidad ni de la vecindad civil adquiridas...), proclama el párrafo tercero del número en estudio que la privación o suspensión en el ejercicio de la patria potestad o el cambio de vecindad civil de los padres, no afectarán a la vecindad civil de los hijos.

D. Mientras que el número $2 .^{\circ}$ del artículo 14 establecía la facultad de optar por la vecindad del lugar de nacimiento, ante el encargado del Registro Civil, dentro del año siguiente a la mayoría de edad o emancipación del interesado, la presente Ley, añade un párrafo al número $3 .^{\circ}$ de meritado artículo, disponiendo que, en todo caso, puede el hijo, desde que cumple 14 años y hasta un año después de su emancipación, optar ya por la vecindad del lugar de su nacimiento, ya por la de cualquiera de la de sus padres, puntualizando que, si no estuviera emancipado, habrá de ser asistido en su opción por su representante legal.

Antípodas en sus respectivos alcances la redacción anterior y la actual, llama ésta la atención por las notas siguientes: $10^{\circ}$ Señalamiento de la edad de 14 años, a partir de la cual cabe la posibilidad de opción de vecindad. $2{ }^{\circ}$ Facultad de opción tan amplia que abarca desde la del lugar de nacimiento, hasta la vecindad de cualquiera de los padres. $3 .^{\circ}$ Ejercicio de la opción hasta que transcurra un año después de la emancipación, lo que conduce al planteamiento de las interrogantes siguientes: a) ¿Es posible la opción dentro del año siguiente a la mayoría de edad, como hasta ahora acaecía? b) ¿Pierde el derecho a optar si no se produce la emancipación? c) ¿Se refiere el inciso final a la necesidad de asistencia en la opción del representante legal, en el lapso comprendido entre los 14 y los 16 años, o se puede considerar válida tal asistencia, y por tanto la opción, aunque siendo mayor de 16 años no hubiera conseguido la emancipación el interesado?

De otro lado, frente a la imposición establecida por el número $4 .^{\circ}$ del comentado artículo 14 , referente a que la mujer casada seguirá la 
condición del marido, se alza la nueva ley proclamando, en rectificación de lo establecido en dichos número y artículo: «El matrimonio no altera la vecindad civil. No obstante, cualquiera de los cónyuges no separados, ya sea legalmente o de hecho, podrá, en todo momento, optar por la vecindad civil del otro.

Finalmente, reproduce la nueva Ley, a la letra, lo referido a la adquisición de la vecindad civil, y a que en caso de duda prevalecerá la vecindad civil que corresponda al lugar de nacimiento, con la única alteración de sustituir los anteriores números 3 y 5 por los 5 y 6 respectivamente.

Artículo 16.

Queda en idéntica redacción su número primero, pero suprimidas las particularidades $3 .^{\mathrm{a}}$ y $4 .^{\mathrm{a} 7}$

Se reproduce el número segundo en toda su literalidad.

Se añade un número tercero, como sigue: «Los efectos del matrimonio entre españoles se regularán por la ley española que resulte aplicable según los criterios del artículo 9 y, en su defecto, por el Código civil.

En este último caso se aplicará el régimen de separación de bienes del Código civil si conforme a una y otra ley personal de los contratantes hubiera de regir un sistema de separación».

No puede merecer peor crítica el desdichado párrafo primero de este número del artículo 16; es su redacción tan confusa, que obliga a lectura repetida, pues que, de la primera, se extrae la disparatada impresión de que los efectos del matrimonio entre españoles se regulará por la ley española. Solamente nuevas, y más atentas, lecturas aclaran que -en cierto modo a semejanza, en este caso feliz, del tratamiento que da la Constitución en su artículo $3 .^{\circ}$ a las lenguas españolas- se trata de españoles sujetos a distintas legislaciones civiles de las que coexisten en España.

Igualmente, resulta incomprensible cómo puede el legislador escribir los siguiente: «...la ley española que resulte aplicable según los criterios del artículo 9 y, en su defecto, por el Código civil». Entonces ¿a 
qué cuerpo legal corresponde el artículos 9 , si en defecto de los criterios en él establecidos debe recurrirse al Código civil?

Resulta penoso constatar como, cada vez más, se deteriora con dislates de inconmensurable calibre la pulquérrima, límpida y castiza redacción originaria de nuestro Código civil.

A manera de anécdota, recordemos que en las redacciones de los antiguos periódicos, existían los llamados «correctores de estilo» cuya misión consistía en pulir, depurar y adecentar sintáctica y semánticamente, los artículos a publicar. Aunque pueda parecer impertinencia, se me ocurre sugerir la contratación de «correctores de estilo» con la misión de adecuar los preceptos legales a los del idioma.

Tampoco hacían falta alforjas para el segundo párrafo del número que nos ocupa (si bien es cierto que en él se aclara lo que pretendía indicar el anterior al referirse a aplicación del Código civil en defecto del artículo 9), teniendo en cuenta que si la ley personal de cada uno de los contrayentes establece el sistema de separación de bienes, hubiera sido duro en tal tesitura imponerles el de la sociedad de gananciales, pongamos como ejemplo. Ahora bien, separación por separación, que sea la que regula el Código.

\section{Artículo 1.066 .}

Únicamente modifica el inciso final del párrafo primero, sustituyendo su anterior redacción: «Si el interés fuera igual, el título se entregará al varón, y, habiendo más de uno, al de mayor edad», por la siguiente: «Si el interés fuere igual, el título se entregará, a falta de acuerdo, a quien por suerte corresponda».

Con un socorrido "al que Dios se la dé San Pedro se la bendiga», borra la redacción del texto cualquier discriminación, no sólo por razón de sexo, sino también por razón de edad.

Artículo 1.267.

Se limita la modificación a la supresión de la referencia al sexo que, para calificar la intimidación, se contaba entre las circunstancias recogidas en la redacción anterior. 
Referencia, la anterior, evidentemente inoportuna en los tiempos que corren, pero de notoria importancia en el pasado, dada por supuesta la debilidad de la mujer, que hacía escribir a Manresa: «La ley, ocupándose principalmente del intimidado, dice que se atienda al sexo y a la edad, circunstancias de influencia bien comprensibles en la energía moral»»."

\section{ARTÍCULO TERCERO}

Dispone la adición al artículo 93 del Código de un párrafo segundo, del tenor siguiente:

«Si convivieran en el domicilio familiar hijos mayores de edad o emancipados que carecieran de ingresos propios, el Juez en la misma resolución, fijará los alimentos que sean debidos conforme a los artículos 142 y siguientes de este Código.»

Tal vez de una lectura rápida y poco meditada podría surgir la impresión de inoportunidad y extravagancia del transcrito párrafo, y ello por los motivos siguientes:

1. En cuanto la comentada Ley, tanto en su rúbrica como en su Preámbulo, proclama su finalidad de reformar determinados artículos del Código civil, con el propósito de acabar con las discriminaciones que, por razón de sexo, aún en él se hallaban; sin embargo, el párrafo en cuestión no se refiere, ni remotamente, al anunciado objeto de la reforma.

$2 .^{\circ}$ Ocurre que los artículos 92 y 94 -precedente y siguiente del que ha sido objeto de ampliación- se refieren a los hijos que estén bajo patria potestad, y, salvo los casos de incapacidad (Vid. el artículo 171 del propio cuerpo legal), los mayores de edad no lo están.

$3 .^{\circ}$ En qué casos serían de aplicación los artículos 1.609 a 1.617 de la Ley de Enjuiciamiento Civil.

Acaso, en contestación a las interrogantes planteadas -más concretamente a la segunda y tercera-, podrían reseñarse las dos corrientes, doctrinal y jurisprudencialmente barajadas, que, empero parecer antitéticas, vendrían a puntualizar, finalmente, los distintos supuestos 
de aplicación atendiendo a las peculiares circunstancias de cada uno de ellos.

Iniciaremos, pues el comentario por la que pudiéramos llamar tradicional u ortodoxa, recogiendo el parecer de algunos ilustres civilistas, y así:

Para Beltrán de Heredia: «de dos formas, según las situaciones, pueden los padres subvenir a las necesidades de los hijos: mediante el cumplimiento del poder-deber de la patria potestad y mediante el cumplimiento de la estricta obligación legal de alimentos. La primera tiene lugar cuando los hijos no están emancipados y, por estar sometidos a la patria potestad, tienen derecho a ser alimentados, educados e instruidos por sus padres...; la segunda tiene lugar cuando los hijos, una vez emancipados y salidos de la patria potestad, se encuentra en un estado de necesidad. Es, pues, después de la emancipación cuando puede originarse una estricta obligación alimenticia entre padres e hijos prevista en el número $2 .^{\circ}$ del artículo $143 . .$. los padres con respecto a sus hijos no emancipados tiene el deber, no sólo de alimentarlos, sino también de educarlos e instruirlos, es decir, de proporcionarles los medios necesarios para que una vez producida la emancipación puedan valerse por sí mismos... Pero... a pesar del empeño y del fiel cumplimiento de aquel deber por parte de los padres, pueden... los hijos no estar en condiciones de poder atender a sus propias necesidades... y, en consecuencia... tener que ser alimentados por los padres. Surge así la típica obligación de alimentos prevista en el número $2 .^{\circ}$ del artículo 143, cuyo supuesto de hecho está constituido por los siguientes requisitos: a) emancipación del hijo, b) filiación... c) posibilidad económica en el padre y d) estado de necesidad en el hijo...».9

En términos similares se manifiesta Cobacho Gómez, al escribir: «Parece claro que hay que distinguir entre la obligación de mantenimiento de los cónyuges y los hijos menores constante matrimonio, de la obligación de alimentos que surge entre determinadas personas. El deber de proceder de alimentos a los hijos menores de edad es independiente de los bienes que tengan éstos y no tiene el carácter de reciprocidad; sin embargo, en la obligación de alimentos «stricto sensu», sí es necesa- 
rio que haya un estado de necesidad y se da la reciprocidad entre alimentante y alimentista». ${ }^{10}$

Abundando en lo expuesto, es de citar el párrafo $10^{\circ}$ del artículo 148 , poniendo como condición de exigibilidad la necesidad del alimentista y como momento inicial del abono el de la fecha en que se interponga la demanda.

Ahora bien, ¿qué demanda? Innegablemente la que origina el procedimiento regulado en los artículos 1.609 a 1.617 de la Ley de Enjuiciamiento Civil, bajo la rúbrica «De los alientos provisionales», cuyo último artículo, negando la excepción de cosa juzgada a la sentencia dictada en tal procedimiento, deja a salvo el derecho de las partes para promover el juicio declarativo correspondiente.

Comentando el procedimiento señalado, anota Manresa: «Esta es la regla general que ha de aplicarse -instanciación mediante referido proceso- sin perjuicio de las excepciones que la misma ley establece. En el artículo 1.100, por ejemplo, se determina la forma en que han de darse alimentos a los herederos, legatarios y cónyuges sobreviviente, durante el juicio de testamentaría; los artículos 1.314 y siguientes tratan de los alimentos del concursado, y el 1.916 de los que deben darse a las personas constituidas en depósito. En todos estos casos y en los demás especiales, se observará el procedimiento establecido respectivamente para cada uno de ellos»."

De entre la abundante jurisprudencia al respecto del Tribunal Supremo, la sentencia de 2 de marzo de 1967 dispone: «...En el aspecto procesal, son notas distintivas de esta institución ( «De los alimentos entre parientes»): a) la instauración de un procedimiento especial, para su exigencia con carácter provisional, que se regula en el Título XVIII del Libro $2 .^{\circ}$ de la Ley rituaria...; b) las consecuencias que, lógica y necesariamente, se derivan de la propia especialidad del procedimiento impide a los demandantes acumular acciones que deban ventilarse y decidirse en juicios de diferente naturaleza, ni oponerse en el acto del juicio, excepciones o cuestiones que desborden la índole del procedimiento que obliga a limitarse a discutir -como expresa el artículo 1.612 de la Ley procesal- la oposición al derecho a los alimentos alegado por el de- 
mandante, o la negativa a la obligación, ya de prestarlos, ya de hacerlo en la cuantía que aquél pida, sin poder traerse al campo de la litis, la validez y el alcance de negocios jurídicos ajenos a la materia concreta del juicio, o que exijan pronunciamiento propios del juicio ordinario declarativo».

También argumento sólido, obstaculizador en alguna forma de la vertiente a introducir mediante el nuevo párrafo al artículo 93 del Código, sería la facultad que concede el artículo 149 del propio Código, al obligado a satisfacer alimentos, a recibir y mantener en su propia casa al que tiene derecho a ellos.

A este respecto, escribe Reverte Navarro: «Desde el punto de vista del alimentante, el recibir en su propia casa al alimentando puede suponer una forma menos gravosa de cumplimiento de su obligación. Parece evidente que el artículo 149 está pensando en la conveniencia económica del obligado al concederle este derecho de optar por una u otra forma de cumplimiento. Y es por esta misma razón por lo que su decisión ha de ser matizada por el criterio del Juez, para que en vista de las circunstancias subjetivas del caso concreto la sola valoración económica no sea decisiva. Habrá el Juez de valorar, esencialmente, si el recibir al alimentado en su casa es conciliable en la vida en común del alimentante $\mathrm{y}$ alimentista». ${ }^{12}$

La segunda vertiente observada, se inscribe dentro de parámetros, tal vez, más acordes con la realidad social de nuestro tiempo, que (establecida la mayoría de edad en los 18 años, de una parte, la dificultad de acceso al primer puesto de trabajo para un gran número de jóvenes -mayores de edad legal, pero sin ingreso alguno-, la dedicación a los estudios hasta avanzada la veintena en otros tantos, etc.), imponía al legislador la necesidad de arbitrar cauces adecuados para asegurar medios suficientes de subsistencia y formación integral a los que, si la ley confiere plenitud de derechos, la razón económica les sujeta a la convivencia y dependencia familiares.

Abierto, entonces, el portillo a través de la interpretación jurisprudencial extensiva de la normativa vigente — - según se verá en líneas siguientes - principios de equidad - y asimismo de economía procesal- 
aconsejaban ventilar y resolver tales cuestiones en un único, rápido y eficaz procedimiento, cual venía a ser el de la separación o divorcio conyugal; habida cuenta de que si en ellos se dilucidan, asimismo, cuestiones relativas a cargas de la familia, que comprenden, obviamente, los auxilios económicos a los hijos menores, ¿qué argumentos podrían esgrimirse, desde postulados de justicia absoluta, para ignorar en dichos procedimientos la suerte de los hijos mayores de edad, que, conviviendo en el domicilio familiar, carecen de ingresos propios?

Al mismo tiempo, y abundando en lo dicho, valga recordar - como resalta Manresa en nota anterior de este trabajo- que no siempre aparece regulado el tema de los alimentos en los artículos 1.609 a 1.617 de la Ley de Enjuiciamiento Civil, sino que la propia Ley regula procedimientos distintos y especiales en determinados casos, de donde no resultaría dislate, ni perturbación alguna, la introducción en nuestro derecho de una nueva fórmula como vendría a ser la del párrafo añadido al artículo 93 del Código civil.

No escapará a la atención del lector que junto a la dificultad de introducir en la demanda de separación o divorcio -o en las medidas provisionales o provisionalísimas - la petición de auxilios económicos para el hijo mayor de edad que, sin recursos, convive en el domicilio familiar, en tanto, a la sazón, situación no regulada por el Código, hallábase el problema relativo a legitimación del cónyuge instante, en orden al ejercicio por sí de acciones correspondientes a persona mayor de edad, de quien carecía de representación legal.

Ambos escollos se resuelven jurisprudencialmente eludiendo la referencia a alimentos - que habrían de ser postulados por el interesado mayor de edad o por su apoderado en el juicio correspondiente- para poner énfasis en el concepto de «cargas familiares» diseñado en el artículo 91 del Código civil.

En punto a lo anterior, puede ser muestra la sentencia de la Audiencia Territorial de Barcelona de 10 de diciembre de 1987. En efecto, presentada la demanda de divorcio por los litigantes cuando la hija del matrimonio era menor de edad, vino a cumplir los 18 años con anterioridad a dictarse sentencia en dicho procedimiento, hecho tenido en cuen- 
ta en el Fundamento de Derecho Cuarto de la Audiencia, del tenor siguiente: «Ello no significa que en la sentencia definitiva no quepa hacer pronunciamiento alguno sobre alimentos en favor de la hija que ya ha alcanzado la mayoría de edad. Al respecto, la Sala, de forma reiterada -sentencias de 24 de abril de 1987, 19 y 20 de mayo de 1987, 23 de enero de 1988, entre otras - ha declarado que en estos procesos de separación o divorcio, los padres, si bien no pueden ejercitar en nombre del hijo o hijos mayores de edad no incapacitados, por carecer de legitimación, las oportunas pretensiones en orden a solicitar una cantidad o pensión económica por alimentos, dicha atribución debe y puede entenderse válidamente instada por uno de los progenitores en tanto y cuanto sirve para el levantamiento de las cargas familiares - artículo 91 del Código civil - ya que mientras alguno de los hijos siga económicamente dependiendo de los padres, éstos deben contribuir a su educación y alimentación. Y, aunque existe un proceso específico para determinar su cuantificación por el cauce sumario de los artículos 1.609 y siguientes de la Ley de Enjuiciamiento Civil, o mediante su ejercicio en el juicio declarativo correspondiente, por economía procesal y buscando una solución justa a los casos frecuentemente acaecidos en la realidad actual, de que la independencia de los hijos no tiene lugar sino mucho después de alcanzada la mayoría de edad, debe estimarse, cuando se reúnan los requisitos y presupuestos legales, las pertinentes peticiones por este concepto dentro del proceso matrimonial entablado, debiendo puntualizarse que su extinción se operará de conformidad con lo dispuesto en el artículo 152 del Código civil...».

Por su parte, la sentencia de la Audiencia Territorial de Pamplona de 8 de octubre de 1987, dispone en su Fundamento de Derecho Segundo: «En cuanto a las medidas económicas acordadas en favor de los hijos del matrimonio, deben adoptarse, a juicio de la Sala... las siguientes, por los motivos que se indican: a) en principio, las pensiones reconocidas a los hijos, no son pensiones alimenticias, o alimentos propiamente dichos, sino, mientras vivan a costa de una de los cónyuges, y no se hayan independizado económicamente, son propiamente compensación a las "cargas del matrimonio o de la familia», conforme se expresan, en tal aspecto, los artículos 90-C y 93, del Código civil, los que determinan, por otro lado, la «contribución» que a tales fines, deberá realizar 
el cónyuge que salga de ese entorno familiar; b) de la anterior premisa, hay que sacar diversas conclusiones, siendo la primera de ellas, la de que la esposa está legitimada activamente para pedir tal ayuda, y no los hijos, aunque hayan cumplido la mayoría legal de edad, por cuanto es aquélla y no éstos, mientras los mismos permanezcan en la familia, por su falta de independencia económica, y al no salir de ella, la que debe pedir para levantar esas cargas cuya dirección y administración corresponde a la misma; c) otra consecuencia de aquella premisa es la de que la carga no se extingue, sin más, automáticamente, con la llegada de la mayoría de edad de los hijos, indirectamente beneficiarios, pues puede prolongarse por cierto tiempo, que en los usos sociales actuales (que sirven de pauta interpretativa a tales preceptos: artículo 3, párrafo $1{ }^{\circ}$ del Código civil) hacen ampliable la dependencia familiar, por regla general, hasta los 23 años, según se viene interpretando habitualmente por esta Sala y otros órganos judiciales, a menos que se prueba una prórroga a esa edad, y que esta edad es en la que suele establecerse una mayor posibilidad de colocación profesional o laboral de los hijos, debiendo, por otro lado, desaparecer tal auxilio si en ese período el hijo o hijos obtienen colocación o cambian de estado, independizándose de la familia, en cuyos casos, si lo necesitan, tendrán que acudir a la vía alimentaria ordinaria, ya como directamente y únicos beneficiarios». ${ }^{13}$

\section{ARTÍCULO CUARTO}

El artículo 159 del Código civil tendrá la siguiente redacción:

«Si los padres viven separados y no decidieren de común acuerdo, el Juez decidirá, siempre en beneficio de los hijos, al cuidado de qué progenitor quedarán los hijos menores de edad. El Juez oirá, antes de tomar esta medida, a los hijos que tuvieran suficiente juicio, y en todo caso a los que fueran mayores de doce años.»

Lo que más urge destacar, al iniciar el comentario de este artículo 159 , es la gratísima sorpresa que produce verlo tratado y reformado por la Ley que nos ocupa; sorpresa tanto más comprensible si se reseña que en la Proposición remitida por el Senado al Congreso que ahora constituye la Ley $11 / 1990$, no se hacía la más mínima alusión al mismo, no obstante ser uno de los artículos más discriminatorios —en esta oca- 
sión para el hombre - de cuantos aún quedaba de parecido jaez dispersos por el Código.

Dicho esto, procede efectuar algunas observaciones:

1. ${ }^{\circ}$ Contempla el supuesto de hecho la circunstancia de la interrupción de la convivencia de los progenitores, y de su falta de acuerdo en relación a cuál de ellos debe corresponder el cuidado del hijo menor.

$2 .^{\circ} \quad$ Planteadas así las cosas, corresponde decidir al Juez, en interés del hijo, a cuál de los progenitores se debe encomendar la custodia del menor.

3. ${ }^{\circ}$ No por mera coincidencia, sino por meditada decisión y reflexión en torno a las leyes $11 / 1981$ y $30 / 1981$-que cita expresamente el legislador - se reitera el criterio implantado por las mismas, ordenando al Juez que, antes de la adopción de cualquier medida, oiga a los hijos que tuvieren suficiente juicio - sobre cuya suficiencia corresponde discernir al propio Juez, como paso previo para acordar o no la audiencia - y, en todo caso, a los que fueren mayores de 12 años. (Edad que, desde las referidas leyes reformadoras del Código civil, se ha fijado como límite genérico y objetivo entre la ingenuidad infantil. y la embrionaria madurez de la inicial pubertad).

4. ${ }^{\circ}$ Evidentemente, el denso contenido del artículo 159 exige unos cauces procedimentales para su necesario discurso; y los tiene, en efecto, en la Disposición transitoria Décima de la Ley 11/1981, estableciendo: «Mientras no se modifique la Ley de Enjuiciamiento Civil, se aplicarán las normas de la Jurisdicción voluntaria a las actuaciones que se sigan: ...2. ${ }^{\circ}$ Para resolver las controversias surgidas en el ejercicio de la patria potestad... En el indicado procedimiento, los recursos se admitirán, en todo caso, en un solo efecto. Quedará siempre a salvo el ejercicio de las acciones correspondientes en la vía judicial ordinaria».

\section{ARTÍCULO QUINTO}

En el artículo $648,1 .^{\circ}$ del Código civil se sustituyen los términos «la honra» por el de «honor». 
En los artículos $648,2 .^{\circ}$ y $1.924,2 .^{\circ}$, B. del Código civil, se sustituye el término «mujer» por «cónyuge».

En el artículo 754, párrafo primero, se sustituyen los términos «de la esposa» por «del cónyuge».

Con referencia a la reforma del número $1 .^{\circ}$ del artículo 648 , no parece mereciera demasiado la pena el cambio de «honra» por «honor», como se deduce tras consultar el Diccionario de la Real Academia, edición de 1970, en pos de aclaración del respectivo significado de ambos términos. Dice el Diccionario:

Honor. 2. Gloria o buena reputación que sigue a la virtud, al mérito o a las acciones heróicas, la cual transciende a las familias, personas y acciones mismas del que se la granjea. 3. Honestidad y recato en las mujeres y buena opinión que se granjean con estas virtudes.

Honra. 2. Buena opinión y fama adquirida por la virtud y el mérito. 5. Pudor, honestidad y recato en las mujeres.

Siendo, pues, casi sinónimos, no se acaba de ver justificado el cambio, a menos que se trate de armonizar el término modificado con el empleado por la L.O. de 5 de mayo de 1982, de protección civil del derecho al honor...

También existe bastante sinonimía en su aplicación a las mujeres, aunque, respecto de ellas, sí puede introducirse un matiz importante. En efecto, hasta aquí - ahora es dudoso que acaezca - una mujer, en lenguaje coloquial, podía ser deshonrada. Sin embargo, no he oído jamás que fuera, con ocasión del mismo hecho, aludida como deshonorada.

Para terminar el casi literario comentario, y no negando pueda haber cierta diferente significación entre deshonor y deshonra, la mutación operada ni aclara, ni desvirtúa, ni hace más preciso o inteligible el párrafo referido del artículo de que se habla.

Ningún comentario exige, como no sea destacar su coherencia con el propósito de la Ley, el retoque que, la en estudio, hace a los artículos $648,2 .^{\circ} ; 1.924,2 .^{\circ}, \mathrm{B}$, y 754 del Código civil. 


\section{ARTÍCULO SEXTO}

Dedicado al artículo 756 del Código civil sobre causas de indignidad, se limita a sustituir la redacción de su número $1 .^{\circ}$, por la siguiente: «Los padres que abandonaren, prostituyeren o corrompieren a sus hijos».

\section{ARTÍCULO SÉPTIMO}

Laconismo en extremo, se limita a decir: "Queda suprimido el último inciso del artículo 852 del Código civil».

Laconismo que más parece excusa, o carencia de argumentos, para justificar dicha supresión, sobre todo si leemos el suprimido inciso: «Asimismo es justa causa para desheredar haber cometido adulterio con el cónyuge del testador».

Seguramente se me podrá tildar de escasamente progresista en este punto, pero, para mí, la causa recogida en el suprimido inciso es más que suficiente para merecer la desheredación.

\section{ARTÍCULO OCTAVO}

Igual de lacónico que el anterior, declara suprimida la causa $3 .^{a}$ del artículo 843 del Código civil que, en su extinta redacción, tenía por causa de desheredación: «Haberse entregado la hija o nieta a la prostitución».

\section{DISPOSICIÓN TRANSITORIA}

«La mujer casada que hubiere perdido su vecindad por seguir la condición de su marido, podrá recuperarla declarándolo así ante el Registro Civil, en el plazo de un año a partir de la publicación de esta Ley.»

La disposición es adecuada, en cuanto permite enmendar situaciones creadas en base a un imperativo legal, como era el del inciso primero del número $4 .^{\circ}$ del artículo 14 del Código civil, cuando ese imperativo legal ya no existe. 
En cualquier caso, habrá de ser precisos en el cómputo del plazo concedido, pues que, olvidando la «vacantio legis», el plazo de un año para decidir comienza a correr, no desde la entrada en vigor de la ley, sino desde su publicación en el B.O.E. de 18 de octubre corriente.

\section{CONSIDERACIONES FINALES}

$1 .^{\mathrm{a}} \quad$ Por arcanas razones, y empero la reforma del Código civil por las Leyes de 13 de mayo y 7 de julio de 1981, sigue vigente, en su totalidad, el Título IV del Libro II de la Ley de Enjuiciamiento Civil, al que remite expresamente la Disposición Adicional 4. ${ }^{a}$ de la citada Ley de 7 de julio, en un tenaz empeño por mantener la anacrónica referencia a la mujer casada; discriminación que el probado buen juicio del intérprete suele corregir en la práctica, y que, asombrosamente, no ha merecido atención alguna correctora en reformas legales posteriores, incluida la presente. ${ }^{14}$

$2 .^{\text {a }} \quad$ Lo propio podría predicarse respecto del artículo 980 del Código civil, asimismo ignorado en la presente Ley, no obstante referirse expresamente al viudo, y no al viudo o a la viuda, como los que le preceden.

3. ${ }^{\text {a }} \quad$ Y ya enmendados los referidos artículos, y algunos otros no citados pero también menesterosos - aunque no viniera al caso en atención al propósito de la Ley que comentamos-, no hubiera resultado censurable la adecuación a los cambios últimamente producidos, de bastantes artículos del Código civil, y sirvan como ejemplo, las referencias al protutor que todavía «colean», o al tutor cuando se debiera decir curador.

$4 .^{a} \quad$ No en este caso, pero sí en muchas recientes leyes, se vienen anunciando reformas que, o tardan en exceso o nunca se realizan, así, como cuando se establece, v. gr., «hasta tanto se modifique la Ley de Enjuiciamiento Civil...» y otras muchas de este estilo que, resaltando la provisionalidad de lo hecho, conllevan el doble defecto de perpetuar lo transitorio y de incumplir lo ofrecido. Valga, pues, esta digresión, para criticar una práctica que se debe, de inmediato, desterrar. 


\section{5. ${ }^{\text {a }} \quad$ Últimamente, y empero no agotadas las observaciones posibles}

a la Ley 11/1990 —-más bien, por el contrario, apuntadas sólo las de mayor relieve- es menester, porque tiempo y espacio mandan, dejar, hasta aquí, este comentario.

\section{NOT A S :}

1. La Proposición de Ley, con más clásico talante, se iniciaba con una Exposición de Motivos, y constaba de sólo seis artículos.

2. En la proposición sólo se pretendía la modificación de loss apartados 2 y 3 del artículo 9.

3. En esta ocasión parece procedente el estudio conjunto y comparativo de los apartados 2." y 3." del artículo 9 .

4. Establecen tales directrices, entre otras, las Resoluciones de la Dirección General de los registros de 7-12-1949; 19-6-1943; 7-4-1952. Vid. también sobre este punto: A. Miaja de la Muela. Derecho Internacional Privado. T. Il. Madrid, 1957, quien realiza breve pero enjundiosa reseña del estado de la cuestión en aquel momento.

5. En la Proposición no se modificaba, ni se hacía referencia alguna al artículo 16 del Código.

6. Seguramente, alguna de las interrogantes apuntadas podrían ser contestadas mediante recurso analógico a la 18/1990 sobre reforma del Código Civil en materia de nacionalidad, a cuyo artículo $20, \mathrm{n} . " 2$, apartados a/, 6/ c/ y d) sobre formulación de la declaración de opción, nos remitimos.

7. No me resisto a reproducir, del trabajo que está siendo objeto de reforma, los siguiente: «Extraña sobremanera que la Proposición de Ley en examen no haga referencia alguna modificativa al artículo 16, ignorando los Estatutos de Autonomia de algunas regiones (v.gr. artículos 7,1. y 9 del de Cataluña), y las Compilaciones de Derecho foral existentes. Modificación que exige, fundamentalmente, la regla $1 .^{\text {a }}$ del número $1 .{ }^{\circ}$ de dicho artículo 16 , al establecer que será ley personal la determinada por la ley civil; párrafo consecuente con el mandato, que se elimina en la Proposición, ínsito en el número 4. " del artículo 14 del Código relativo a que la mujer adquiere la condición del marido, pero fuente de conflicto desde la perspectiva de la nueva pretendida redacción».

Como nota a este párrafo, se escribía: «Más que como pura anécdota, podría plantearse la hipótesis de matrimonio, sin otorgar capitulaciones, contraído por personas sujetas una al Derecho común y otra al Derecho foral catalán, decidiendo ambas conservar su respectiva vecindad. Establecidos regímenes económico-matrimoniales distintos - gananciales y de separación - ¿qué ley sería de aplicación, caso de separación o disolución del matrimonio, relativamente al régimen económico del matrimonio, la común o la foral? 
Partícipe, sin duda, el legislador de esta misma preocupación, ha procedido a poner remedio a la cuestión, introduciendo también el artículo 16 en el saco de la reforma, consciente de la imprescindibilidad de su modificación y adaptación a la actual circunstancia.

8. J.M. Manresa Navarro. Comentarios al Código civil español. T. VIII. Pág. 598. Madrid, 1929.

9. Beltrán de Heredia. Comentarios al Código civil y Compilaciones forales. Dirigido por Albaladejo. T: III, V.2. Pág. 38.

10. Cobacho Gómez. La deuda alimenticia. Págs. 11-12. Madrid, 1990.

11. Manresa Navarro. Comentarios a la Ley de Enjuiciamiento Civil. T. VI. Pág. 69. Madrid, 1910 (nótese que las personas constituidas en depósito son ahora las beneficiarias de las medidas provisionalísimas, provisionales y, en general, de las adoptadas en los procedimientos de separación y divorcio.

12. Reverte Navarro. La Intervención judicial en las situaciones familiares. Pág. 140. Murcia, 1980. Adulciguando el rigor del articulo 149, multitud de sentencias, alguna de las cuales cita Reverte.

13. En la misma línea que las sentencias reseñadas, se inscriben, entre otras, la de 5 de marzo de 1984 de la Audiencia Territorial de Oviedo, y la de 9 de noviembre de 1986, de la Audiencia Territorial de Cáceres.

14. L.F. Saura Martínez. «De los efectos y medidas provisionalísimos en la Ley 30/81». Revista Justicia. Pág. 70. 1982. 